\title{
The Effects of Extrafine Beclometasone/Formoterol (BDP/F) on Lung Function, Dyspnea, Hyperinflation, and Airway Geometry in COPD Patients: Novel Insight Using Functional Respiratory Imaging
}

\author{
Jan De Backer, MSc, PhD, ${ }^{1}$ Wim Vos, MSc, PhD, ${ }^{1}$ Samir Vinchurkar, MSc, PhD, \\ Cedric Van Holsbeke, MSc, PhD,', Gianluigi Poli, MSc, PhD, ${ }^{2}$ Rita Claes, BSc, \\ Rodrigo Salgado, $\mathrm{MD}, \mathrm{PhD}^{4}$ and Wilfried De Backer, $\mathrm{MD}, \mathrm{PhD}^{3}$
}

\begin{abstract}
Background: The efficacy of inhaled corticosteroids (ICS) in moderately severe COPD patients remains unclear. At the same time, the use of extrafine particles in COPD patients is a topic of ongoing research.

Objectives: This study assessed the effect of ICS in steroid-naïve mild COPD patients and the effect of reducing the ICS dose in more severe COPD patients previously using ICS when switching to an extrafine particle BDP/F formulation (Foster using Modulite technology, Chiesi Pharmaceutici, Parma, Italy).

Methods: Novel functional respiratory imaging (FRI) methods, consisting of multi-slice CT scans and Computational Fluid Dynamics, were used in combination with conventional pulmonary function tests and patient reported outcomes.

Results: The study showed that the administration of extrafine BDP/F after $4-6 \mathrm{~h}$ led to a significant improvement in lung function parameters and hyperinflation as determined by spirometry, body plethysmography, and functional respiratory imaging. After 6 months of treatment, it was observed that, compared to baseline, the hyperinflation on lobar level at total lung capacity was significantly reduced $(-1.19 \pm 7.19 \% \mathrm{p}, p=0.009)$. In addition, a significant improvement in SGRQ symptom score was noted in the entire patient population. Patients who improved in terms of hyperinflation also improved their MMRC dyspnea score. CFD indicated a difference in regional deposition between extrafine and non-extrafine formulations with $-11 \%$ extrathoracic deposition and up to $+4 \%$ lobe deposition for the extrafine formulation.

Conclusions: The study showed that the administration of extrafine BDP/F improved lung function parameters and hyperinflation. Patients previously treated with ICS remained stable despite the lower dose, while ICS naïve patients improved in terms of lobar hyperinflation. FRI seems to be a sensitive biomarker to detect clinically relevant changes that are not detected by spirometry. The next step is to confirm these findings in a controlled trial.
\end{abstract}

\section{Introduction}

$\mathbf{C}$ HRONIC OBSTRUCTIVE PULMONARY DISEASE (COPD) is a multicomponent disease that includes airway inflammation, airflow limitation, mucociliary dysfunction, and airway structural changes. ${ }^{(1)}$ The hallmark of COPD is, beside the destruction of the lung tissue and capillaries, expiratory flow limitation, which is slowly progressive and irreversible. ${ }^{(2-4)}$ Specific lung function tests, including flowvolume loops, $\mathrm{N}_{2}$ wash-out, and helium flow-volume loops, are typically performed to evaluate the small airway function. ${ }^{(5)}$ Recently, advanced imaging techniques such as multi-slice high resolution CT have been used. ${ }^{(6)}$ This technique allows evaluation of the density of the parenchyma and

\footnotetext{
${ }^{1}$ FluidDA NV, 2550 Kontich, Belgium.

${ }^{2}$ Chiesi Pharmaceutici, 43100 Parma, Italy.

Departments of ${ }^{3}$ Pulmonology and ${ }^{4}$ Radiology, University Hospital Antwerp, 2650 Edegem, Belgium.
} 
reconstruction of the airways in 3D. Very recently, we developed a functional respiratory imaging (FRI) technique combining CT imaging with computational fluid dynamics (CFD). With CFD, based on the CT-derived geometry of the airways, it became possible not only to reconstruct the geometry of the distal airways but also to measure the overall resistance of airways and regional aerosol deposition characteristics at the more peripheral level such as the smaller airways starting from the third bifurcation. Lung volumes can be assessed in more detail at the lobar level, leading to a more granular description of hyperinflation. In previous studies, we demonstrated very good correlations between spirometric indices such as Forced Expiratory Volume in one second $\left(\mathrm{FEV}_{1}\right)$ and $\mathrm{FEV}_{1} / \mathrm{FVC}$ (Forced Vital Capacity) index with the FRI parameters. Therefore, the use of FRI may allow following the functional and anatomic changes in the small
Table 1. Patient Demographics and Baseline Pre-Bronchodilation Lung Function and SGRQ

\begin{tabular}{|c|c|c|c|}
\hline & $\begin{array}{c}\text { GOLD II } \\
(\mathrm{n}=15)\end{array}$ & $\begin{array}{c}\text { GOLD III } \\
(\mathrm{n}=8)\end{array}$ & $\begin{array}{c}G O L D I V \\
(\mathrm{n}=4)\end{array}$ \\
\hline [years] & 806 & 7.11 & 67.2 \\
\hline $\begin{array}{l}\mathrm{FEV}_{1} \\
{[\% \text { pred] }}\end{array}$ & & & \\
\hline $\begin{array}{c}\mathrm{FEV}_{1} / \mathrm{VC} \\
{[\%]}\end{array}$ & $43.13 \pm 9.43$ & $35.00 \pm 8.37$ & $40.00 \pm 13.78$ \\
\hline SGRQ [-] & $44.52 \pm 16.78$ & $44.79 \pm 15.10$ & $48.15 \pm 11.07$ \\
\hline $\begin{array}{l}\text { FRC } \\
{[\% \text { pred }]}\end{array}$ & $150.27 \pm 28.07$ & $160.13 \pm 28.27$ & $146.50 \pm 48.86$ \\
\hline $\begin{array}{l}\text { TLC } \\
{[\% \text { pred] }}\end{array}$ & $121.13 \pm 17.92$ & $117.50 \pm 16.56$ & $114.50 \pm 34.31$ \\
\hline
\end{tabular}

Table 2. Medication Prior to Study Inclusion and Associated Inhalers

\begin{tabular}{|c|c|c|c|c|c|c|c|c|c|}
\hline $\mathrm{Nr}$ & Age & Gender & Stage & $\begin{array}{c}\text { Lung medication } \\
\text { before V1 }\end{array}$ & $\mathrm{Nr}$ & Age & Gender & Stage & Lung medication before VI \\
\hline 1 & 60 & M & GOLD 3 & $\begin{array}{l}\text { Serevent } 25 \mu \mathrm{g} 2 \times 1 / \text { day } \\
\text { Spiriva }\end{array}$ & 15 & 68 & M & GOLD 3 & $\begin{array}{l}\text { Oxis } 9 \mu \mathrm{g} 2 \times 1 / \text { day } \\
\text { Spiriva } \\
\text { Duovent PRN } \\
\text { Pulmicort } 200 \mu \mathrm{g}, 2 \times 2 / \text { day }\end{array}$ \\
\hline 2 & 53 & M & GOLD 4 & $\begin{array}{l}\text { Seretide } 25 \mu \mathrm{g} / 250 \mu \mathrm{g} \\
2 \times 2 / \text { day } \\
\text { Spiriva } \\
\text { Duovent PRN }\end{array}$ & 16 & 64 & $\mathrm{~F}$ & GOLD 3 & $\begin{array}{l}\text { Spiriva } \\
\text { Seretide } 50 \mu \mathrm{g} / 500 \mu \mathrm{g} 2 \times 1 / \text { day }\end{array}$ \\
\hline 3 & 81 & M & GOLD 4 & $\begin{array}{l}\text { Serevent } 50 \mu \mathrm{g} 1 \times / \text { day } \\
\text { Spiriva }\end{array}$ & 17 & 73 & M & GOLD 2 & $\begin{array}{l}\text { Spiriva } \\
\text { Acetylcysteïne } 600 \mathrm{mg} \\
\text { Ventolin PRN }\end{array}$ \\
\hline 4 & 63 & $\mathrm{~F}$ & GOLD 2 & Spiriva & 18 & 51 & $\mathrm{~F}$ & GOLD 2 & $\begin{array}{l}\text { Spiriva } \\
\text { Seretide } 25 / 2502 \times 2 / \text { day } \\
\text { Duovent PRN }\end{array}$ \\
\hline 5 & 65 & M & GOLD 3 & $\begin{array}{l}\text { Seretide } 50 \mu \mathrm{g} / 500 \mu \mathrm{g} \\
\quad 2 \times 1 / \text { day } \\
\text { Spiriva } \\
\text { Duovent PRN }\end{array}$ & 19 & 47 & $\mathrm{~F}$ & GOLD 2 & $\begin{array}{l}\text { Spiriva } \\
\text { Serevent } 50 \mu \mathrm{g} 2 \times 1 / \text { day } \\
\text { Ventolin PRN }\end{array}$ \\
\hline 6 & 48 & M & GOLD 3 & $\begin{array}{l}\text { Seretide } 25 \mu \mathrm{g} / 250 \mu \mathrm{g} \\
2 \times 2 / \text { day } \\
\text { Spiriva } \\
\text { Duovent PRN }\end{array}$ & 20 & 72 & M & GOLD 2 & $\begin{array}{l}\text { Symbicort } 4,5 \mu \mathrm{g} / 160 \mu \mathrm{g} \\
2 \times 1 / \text { day } \\
\text { Spiriva } \\
\text { Duovent PRN } \\
\text { Acethylcsteïne } 600 \mathrm{mg} \\
2 \times / \text { day } \\
\text { Montelukast } 10 \mathrm{mg}\end{array}$ \\
\hline 7 & 65 & M & GOLD 3 & $\begin{array}{l}\text { Seretide } 50 \mu \mathrm{g} / 500 \mu \mathrm{g} \\
2 \times 1 / \text { day } \\
\text { Spiriva } \\
\text { Duovent PRN }\end{array}$ & 21 & 65 & M & GOLD 2 & $\begin{array}{l}\text { Spiriva } \\
\text { Symbicort } 4,5 \mu \mathrm{g} / 160 \mu \mathrm{g} \\
2 \times 2 / \text { day } \\
\text { Duovent PRN }\end{array}$ \\
\hline 8 & 73 & M & GOLD 2 & $\begin{array}{l}\text { Serevent } 50 \mu \mathrm{g} 2 \times 1 / \text { day } \\
\text { Spiriva } \\
\text { Duovent PRN }\end{array}$ & 22 & 64 & M & GOLD 2 & $\begin{array}{l}\text { Seretide } 50 \mu \mathrm{g} / 250 \mu \mathrm{g} 2 \times 1 / \text { day } \\
\text { Spiriva }\end{array}$ \\
\hline 9 & 64 & M & GOLD 2 & $\begin{array}{l}\text { Serevent } 50 \mu \mathrm{g} 2 \times 1 / \text { day } \\
\text { Spiriva } \\
\text { Duovent PRN } \\
\text { Acetylcysteïne } 600 \mathrm{mg}\end{array}$ & 23 & 63 & $\mathrm{~F}$ & GOLD 2 & $\begin{array}{l}\text { Spiriva } \\
\text { Symbicort Forte } 9 \mu \mathrm{g} / 320 \mu \mathrm{g} \\
2 \times 1 / \text { day } \\
\text { Duovent PRN puff and aerosol } \\
\text { Lysomucil } 600 \mathrm{mg} \text { PRN }\end{array}$ \\
\hline
\end{tabular}


TABle 2. (CONTINUED)

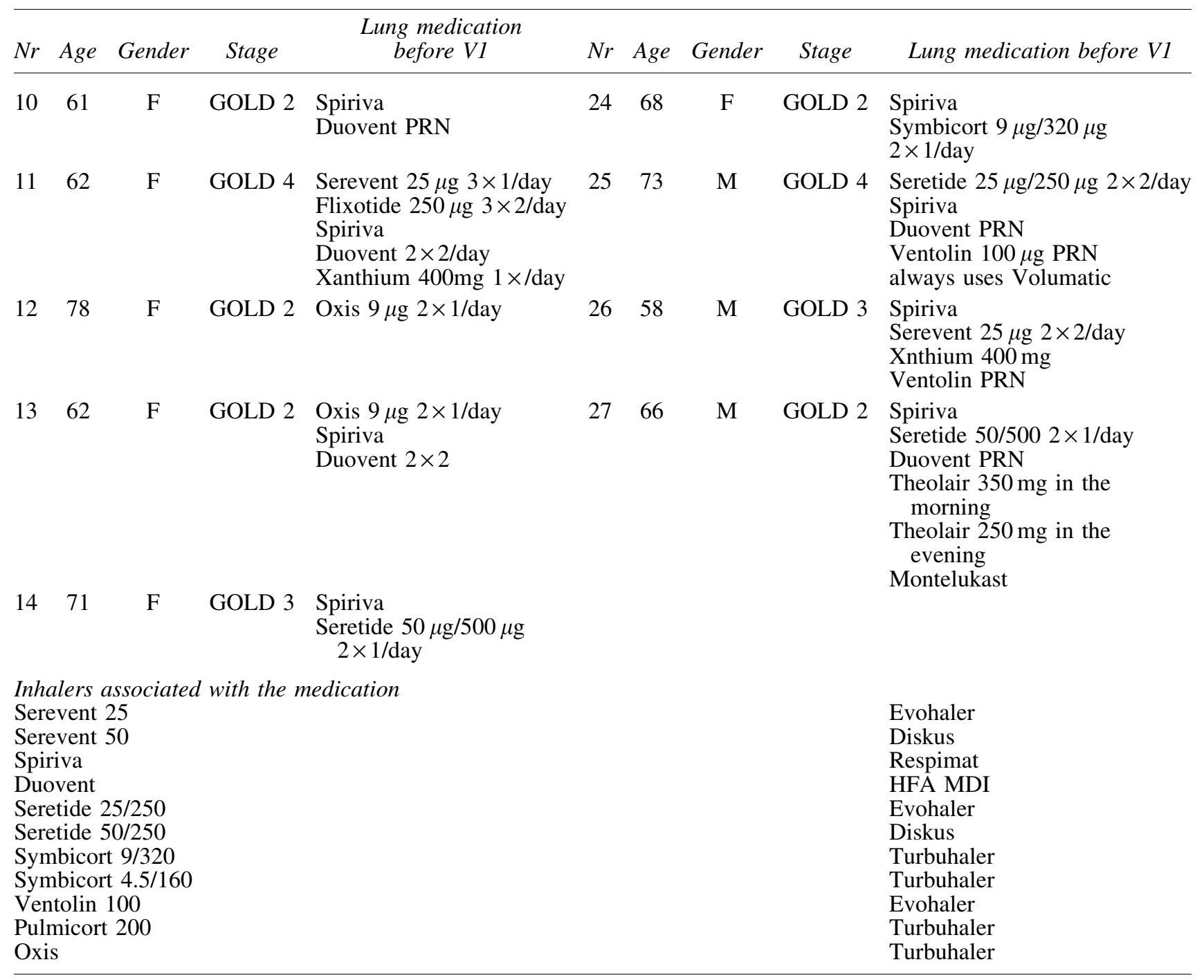

airways after pharmacological interventions both in asthmatics and COPD patients. ${ }^{(7-10)}$

During the last 10 years, inhaled corticosteroids (ICS) and long-acting $\beta_{2}$ agonists (LABA) combination therapy has come forward to treat COPD patients. The concomitant use of ICS and LABA can influence airway obstruction, mucociliary dysfunction, and airway inflammation. ${ }^{(1,11)}$ Furthermore, use of ICS in combination with LABA in a single inhaler shows significant additional improvements on pulmonary function and reduction in symptoms and exacerbations, compared with individual components. ${ }^{(12-15)}$ At present, the effect of inhaled ICS/LABA combination on individual airways and lung volumes remains unclear, and in particular, the effect of ICS in moderate COPD is uncertain. The role of aerosol deposition and the influence of extrafine particles with a lower ICS dose is subject of continuous research. ${ }^{(16,17)}$ The current study explored the effect of an extrafine particle BDP/F formulation (Foster using Modulite technology, Chiesi Pharmaceutici, Parma, Italy) in COPD patients after 6 month treatment using pulmonary function tests and sensitive FRI tools, with specific focus on lobar and airway volumes and resistance, to assess the effect at the level of small airways. Both steroid naïve (moderate COPD patients) and steroid users (severe COPD patients) were included in the patient cohort to assess the effect of extrafine particle ICS in moderate COPD.

\section{Methods}

\section{Patients}

This study enrolled 27 evaluable COPD patients stage II to IV. Patients had a smoking history of at least 10 packyears and an $\mathrm{FEV}_{1} / \mathrm{FVC}$ ratio below 0.70 . Male $(n=16)$ and female $(n=11)$ patients were included with age above 40 years. All patients were treated according to the GOLD guidelines before entering the study. Patient demographics and characteristics according to GOLD classification can be found in Table 1.

\section{Study design}

This study was an open-label, prospective pilot study. The patients received the extrafine beclometasone dipropionate and formoterol fumarate (BDP/F) combination therapy for 24 weeks. They were followed for 7 months before the start of 
the study when they switched to the extrafine formulation. During this 7-month period they were treated with inhaled steroids or fixed combinations with a non-extrafine particle formulation (i.e., no Foster or QVAR). Patients were evaluated twice for their lung function and clinical status (at 7 and 3 months before the switch). At baseline visit, patients received all tests (FRI, pulmonary function tests, and patient reported outcomes) before and after bronchodilation. At the 6 months visit, patients again received all tests before bronchodilation (pre-dose).

\section{Medication}

The study medication (Foster, Chiesi Pharmaceutici, Italy) is a fixed combination containing extrafine beclometasone dipropionate and formoterol fumarate in a HFA Modulite ${ }^{\circledR}$ pMDI device $\left(\mathrm{MMAD}=1.33\right.$; GSD = 1.97). ${ }^{18}$ Each metered dose (ex-valve) contains 100 micrograms of beclometasone dipropionate and 6 micrograms of formoterol fumarate dihydrate. In this study, patients inhaled the $6 \mu \mathrm{g}$ formoterol and $100 \mu \mathrm{g}$ beclometasone dipropionate combination therapy twice in the morning and twice in the evening.

\section{Image post-processing}

The CT settings used were: tube voltage, $120 \mathrm{kV}$; tube current, 10 (low weight patients)-100 (high weight patients) mAs; noise factor, 28; collimation, $0.625 \mathrm{~mm}$; rotation time, $0.6 \mathrm{sec}$; and pitch factor, 1.375 . The field of view was indicated by the CT technician based on the scout image and was positioned closely around the thorax to optimize in-plane image resolution, which was approximately $0.5 \mathrm{~mm}$. The resulting radiation dose was in the order of $1-2 \mathrm{mSv}$ per scan. Images were reconstructed to a slice thickness of $0.6 \mathrm{~mm}$ to attain near cubic voxels. Respiratory gating was used to ensure the proper lung volume to facilitate comparison between baseline and follow-up images. Post-processing of the CT images included segmentation of the airway tree structure, the lung lobes, and CFD flow simulations. Segmentation consisted of grouping voxels that belong to one anatomical structure such as the lung, the lobes, or the airway tree. This group of voxels or mask can subsequently be used to create a patient-specific three-dimensional model of the anatomical structure under consideration. The software package that was used was FDA-approved (Mimics, Materialise, Leuven, Belgium). These patient specific models were the basis for flow simulations using Computational Fluid Dynamics (CFD). More details on the segmentation and CFD principles can be found in previously published studies. ${ }^{(7-10,19)}$

\section{Assessments}

The parameters obtained with functional respiratory imaging and used as primary outcome were:

- Airway volumes specific for the lung volume (siVaw): the airway volumes are direct measurement from the CT scans and include the airways with a diameter larger then 1-2 mm. Around 255 airways are typically included in the patient specific geometry, which corresponds to around 7 generations of airways. The airway volume is a function of the lung volume. To allow comparison of the volumes at different measurement points, the airway volume is normalized by dividing by the lobe volume. The same number of airways are present the baseline and follow-up measurements (see Fig. 3).

- Specific airway resistance (siRaw): airway resistance is calculated using CFD. CT-based lobe expansion from expiration to inspiration was used as boundary conditions to ensure the internal airflow distribution in the CFD calculation matches the patient's real internal airflow distribution. CFD yields total pressure drops and airflow, the resistance is ratio between the two. More information can be found in De Backer et al. ${ }^{(19)}$

- Lobar volumes at functional residual capacity (iVlobes_ FRC).

- Lobar volumes at total lung capacity (iVlobes_TLC).

Lobar volumes are determined by first segmenting the lung volumes and the fissures; subsequently the fissures are used as cutting planes to determine the lobar volume.

The following parameters were obtained with the lung function tests:

- Dynamic lung volumes: Forced expiratory volume in one second $\left(\mathrm{FEV}_{1}\right)$, forced vital capacity ( $\left.\mathrm{FVC}\right)$, peak expiratory flow (PEF), Maximal expiratory flow at $50 \%$ of expired vital capacity (MEF50), Maximal expiratory flow at $25 \%$ of expired vital capacity (MEF25).

- Static lung volumes: Vital capacity (VC), Inspiratory vital capacity (IVC), Functional residual capacity (FRC), Total lung capacity (TLC).

- Airway resistances: Airway resistance (Raw), Specific airway conductance (SGaw), based on body plethysmography.

Further assessments were:

- Functional dyspnea (MMRC dyspnea scale).

- Saint George Respiratory Questionnaire (SGRQ).

\section{CFD based deposition analysis}

To understand the changes in deposition when switching to extrafine particles, a CFD-based deposition analysis was performed in one patient. The baseline model was coupled with the inhaler of the medication the patient previously used (i.e., Oxis Turbuhaler; MMAD $=2.64 ; \mathrm{GSD}=1.91))^{(20)}$ and with the Foster inhaler. Two CFD-based deposition analysis were performed using the methodology described and validated in De Backer et al., ${ }^{(7)}$ one with the original inhaler and the corresponding formulation and one with the Foster inhaler with the extrafine particle formulation. Since the main aim of these simulations was to determine differences in deposition due to particle size, the same inhalation profile was used for both scenarios ( 3 second inhalation with $60 \mathrm{~L} / \mathrm{min}$ peak flow). These analyses provided regional aerosol deposition characteristics. No exhaled fraction was assumed for both scenarios.

\section{Statistics}

Statistical analysis was performed using Statistica 9.1 (StatSoft, Tulsa, OK, USA). Changes in individual parameters after 6 months of treatment with the study medication were evaluated using Wilcoxon matched pairs analysis. Correlations between the changes in different parameters were evaluated using Spearman correlations. Stability of the baseline 7-month period was evaluated with ANOVA. Data are presented as mean \pm standard deviation. 


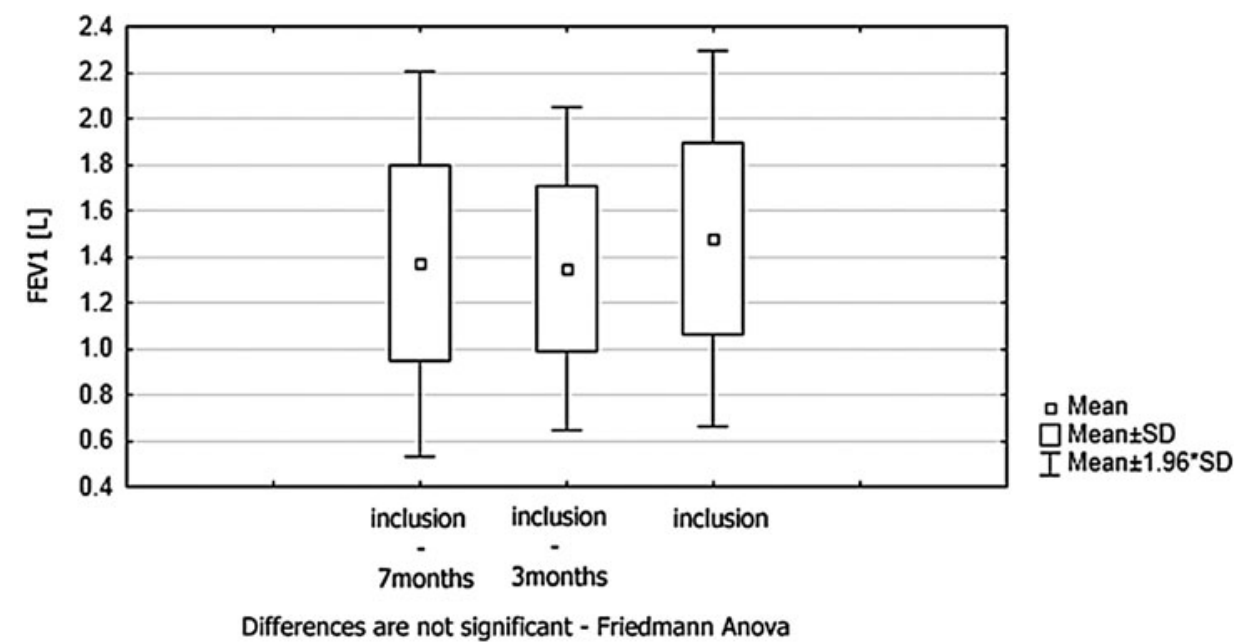

FIG. 1. $\mathrm{FEV}_{1}[\mathrm{~L}]$ at two time points prior to inclusion demonstrate that patients were stable and controlled before entering the study.
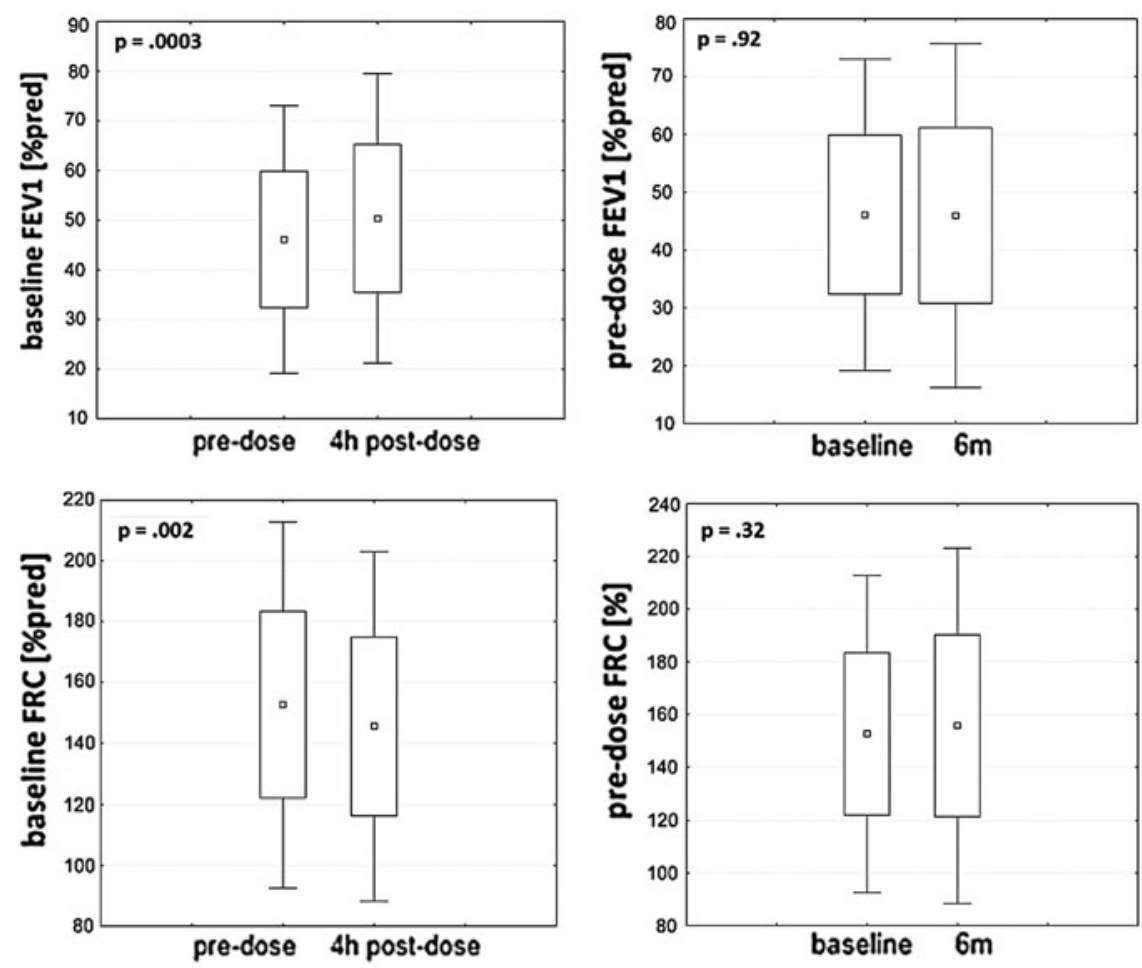

FIG. 2. Changes in $\mathrm{FEV}_{1}$, TLC, and FRC $4 \mathrm{~h}$ at pre-dose and after drug administration at Day 1 (left) and between pre-dose at D1 and after 6 months of treatment (right).
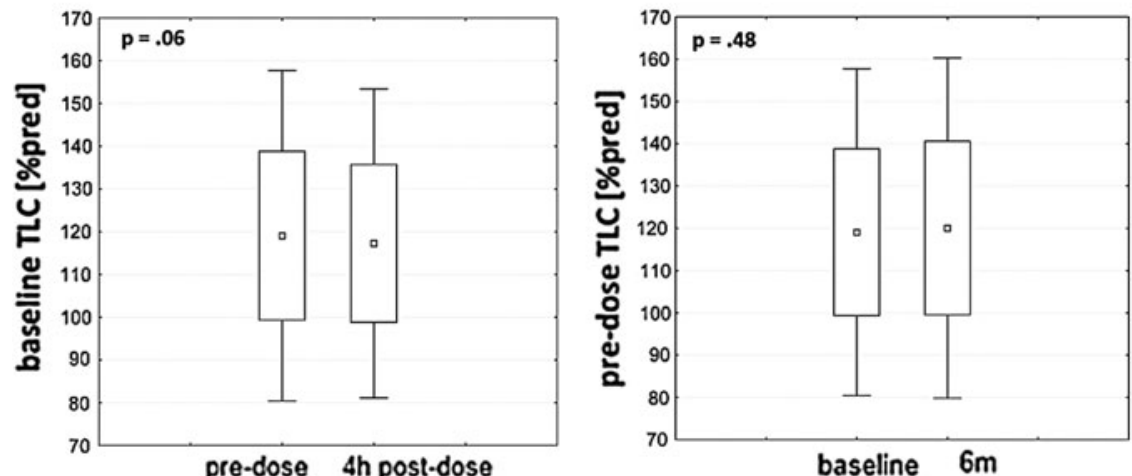

Mean

Mean \pm SD

工 Mean $\pm 1.96 *$ SD 


\section{Ethics}

Approval from the ethical committee of the University Hospital in Antwerp was obtained and patients all gave their informed consent (NCT01204034). The study started September 2010 and ended June 2012.

\section{Results}

\section{Lung function during initial 7 month treatment} with non-extrafine particles

All patients were treated with non-extrafine particles compounds during a 7-month period prior to the switch (Table 2). During this period, lung function measurements were performed at 7 months and 3 months prior to the switch. The results are given in Figure 1. There were no significant changes in the FEV1 during this period, nor were patients considered to be clinically unstable since their medication was not altered and their symptoms did not change significantly.

\section{Post-bronchodilation effect 4-6h after administration of extrafine particle compound}

The data showed that, 4-6h after the administration of the drug, FEV1 \% predicted values increased significantly from $46 \pm 14 \%$ to $50 \pm 15 \%$ ( $p=0.0003)$. Concomitantly, hyperinflation decreased significantly as indicated by a reduction in FRC of $7 \pm 10 \%$ pred $(p=0.002)$. The TLC also decreased, just missing the statistical significance threshold $(p=0.06)$ (Fig. 2). No differences were observed between the ICS naïve patients and the ICS users for the PFTs. The FRI data showed a highly significant increase in siVaw (Fig. 3) from 0.0019 \pm 0.001 to $0.0021 \pm 0.001(p<0.00001)$ and a highly significant reduction in siRaw from $0.23 \pm 0.26 \mathrm{kPas}$ to $0.15 \pm 0.11 \mathrm{kPas}$ $(p<0.00001)$ (Fig. 4). No differences were observed between the ICS naïve patients and the ICS users for siVaw and siRaw. When assessing the changes in lobar volumes using imaging, a significant reduction was observed both in iVlobes_ FRC and iVlobes_TLC $(p<0.00001)$. ICS naïve patients reduce more in terms of acute iVlobes_FRC $(p=0.0045)$ and iVlobes_TLC $(p=0.001)$ compared to the ICS users.

\section{Pre-bronchodilation effect after 6 months of treatment with the small particle compound}

After 6 months of treatment, the pre-bronchodilation measures were compared with the pre-bronchodilation values at baseline. Both spirometry (FEV1) and body plethysmography values (FRC and TLC) did not change significantly (Fig. 2). Also no significant change in siVaw $(p=0.65)$ and siRaw ( $p=0.16$ ) was observed (Fig. 4). However, interestingly, the Wilcoxon matched pairs test on the imaging data at the lobar level showed a significant reduction in lobar volume at TLC (iVlobes_TLC, $-1.19 \pm 7.19 \%$ p, $p=0.009$ ) (Fig. 5); this change was driven by the ICS naïve patients. A borderline

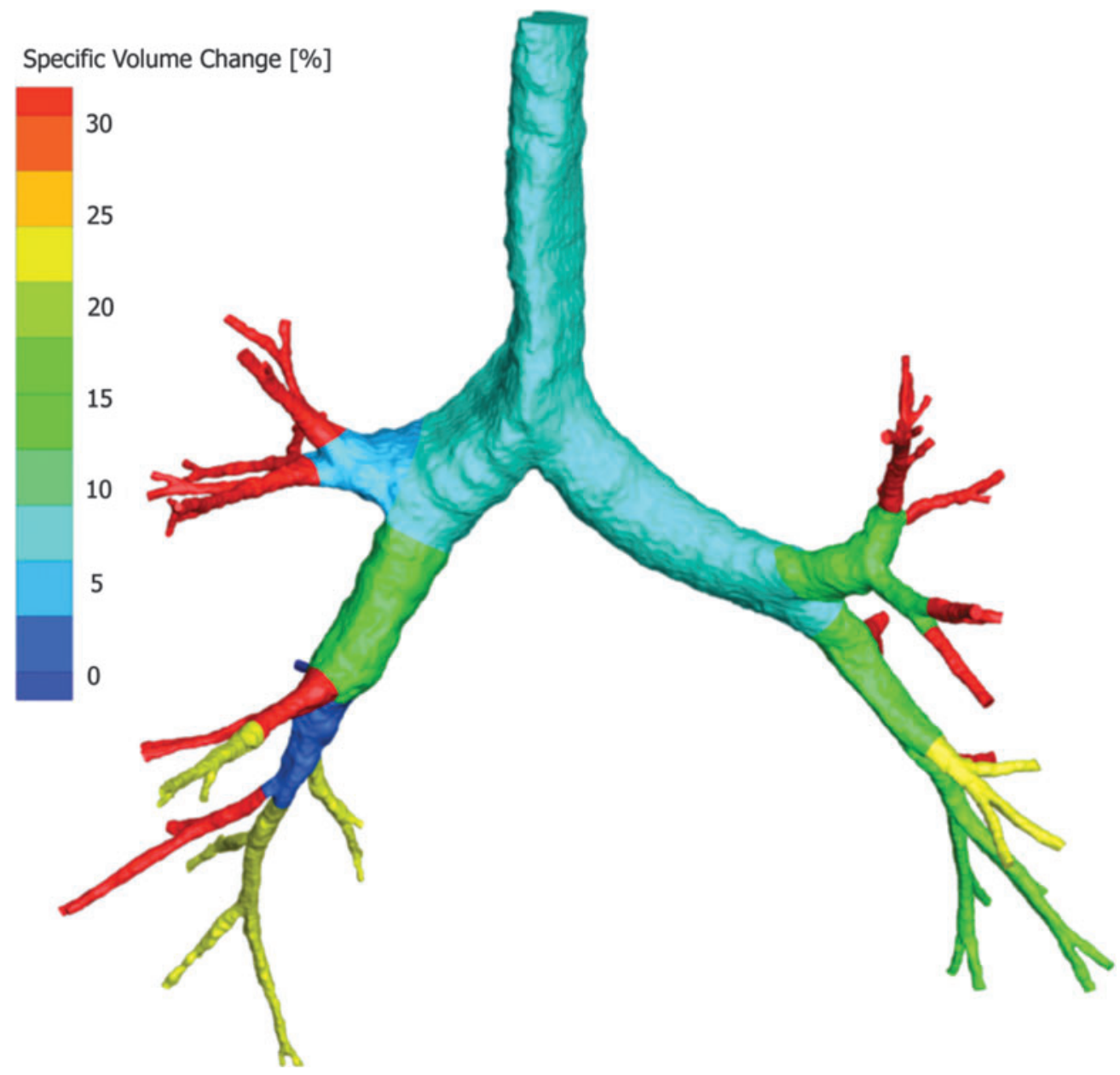

FIG. 3. Changes in siVaw [\%] $4 \mathrm{~h}$ after bronchodilation. 

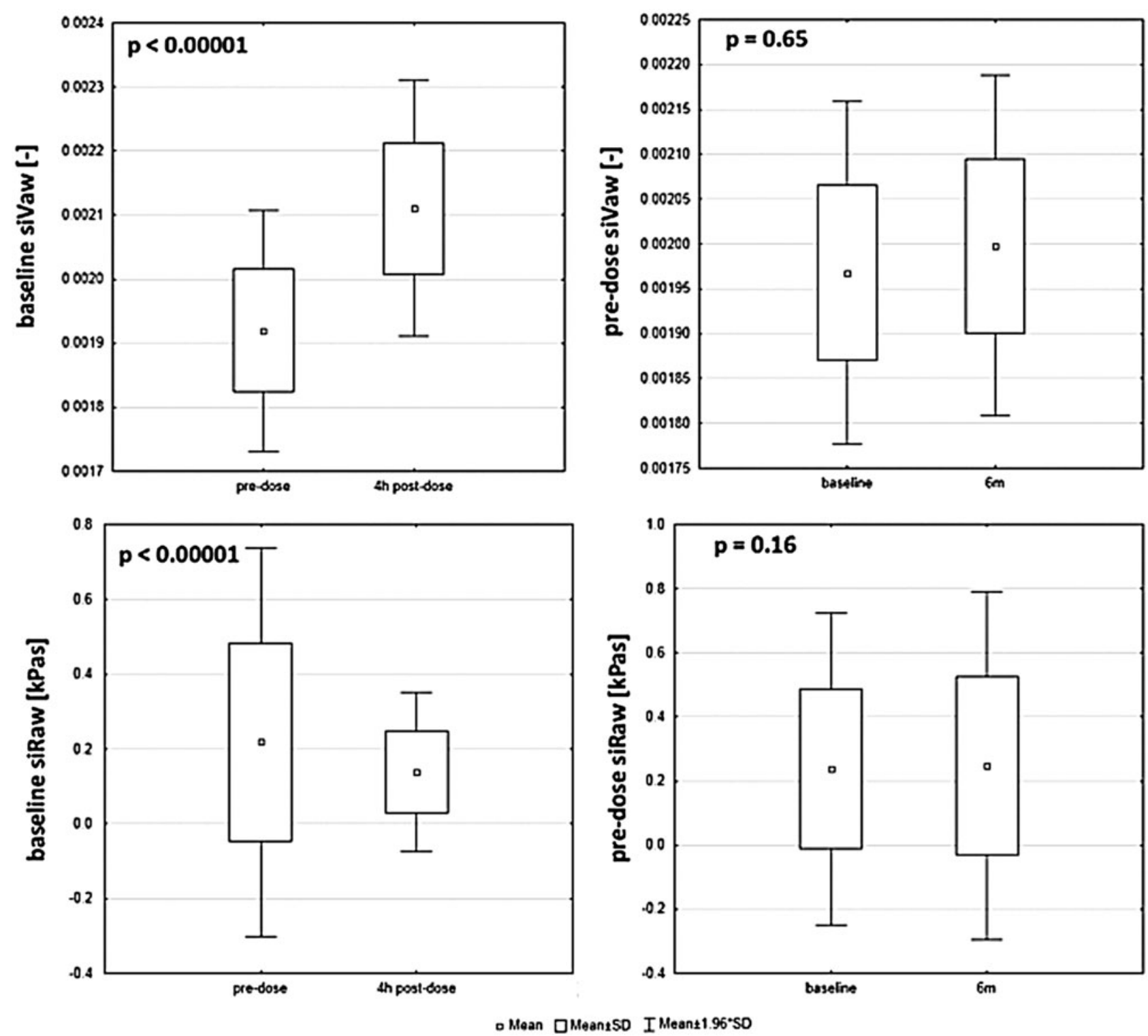

FIG. 4. Changes in siVaw and siRaw at pre-dose and after drug administration at Day 1 (left) and between pre-dose and Day 1 after 6 months of treatment (right).

but significant difference in iVlobes_TLC change between ICS naïve patients and ICS users was observed $(p=0.044)$. SGRQ symptoms score indicated a significant improvement $(p=0.04)$ after 6 months (Fig. 6). The MMRC score showed a link between the change in dyspnea feeling and the change in lobar hyperinflation measured at TLC (iVlobes_TLC). Patients who reported an improvement in MMRC score equal or greater than 1 had a significantly greater $(p=0.0024)$ reduction lobar iVlobes_TLC volumes compared to patients who reported a decline in MMRC by 1 or greater. The group of patients who reported no change in MMRC score had no reduction $(p>0.05)$ in the lobar iVlobes_TLC level. No difference in patient reported outcome changes were observed between ICS naïve patients and ICS users. When comparing the change in pre-bronchodilation iVlobes_TLC with the acute (4-6h) change in iVlobes_TLC, a significant positive correlation $(r=0.44, p<0.00001)$ was observed with a slope of approximately 0.78 (Fig. 7). This would mean that around $78 \%$ of the acute, post-bronchodilation change effec- tively remains after 6 months of treatment. Furthermore, a highly significant negative correlation $(r=-0.40 ; p<0.00001)$ was found between the pre-bronchodilation iVlobes_FRC and the acute change in iVlobes_FRC after drug intake. This indicated that the more hyperinflated the patients were prior to receiving the medication, the more they tend to deflate with treatment (Fig. 8).

\section{CFD-based deposition patterns}

To assess the link between the change in deposition and the change in lobar volume, CFD was used to determine the deposition patterns in patient 14. Figure 9 illustrates the coupling between the patient specific model of patient 14 and the Oxis Turbuhaler and Foster pMDI. It could be observed that the lung dose reaching the lower airways is larger for the extrafine particle formulation compared to the non-extrafine particle formulation with a reduction in extrathoracic deposition of $11 \%$ and an increase in lobe deposition up to $4 \%$ for 
Change in iTLC [\% pred] $4-6 \mathrm{~h}$ post bronchodilation

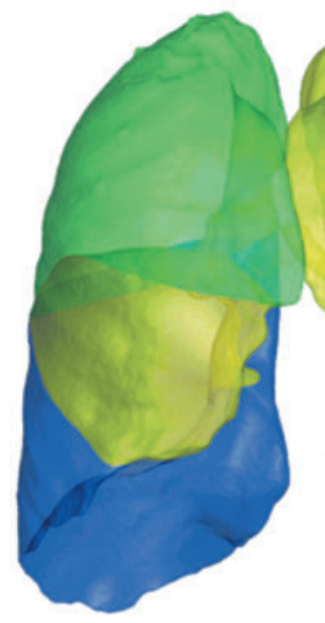

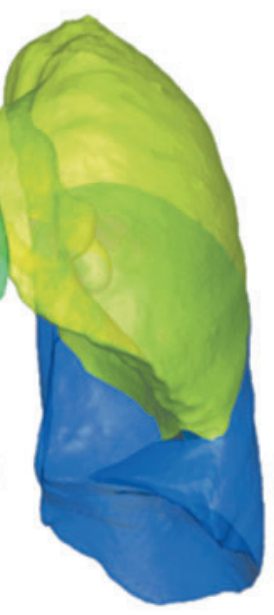
Change in iTLC [\% pred] after 6 months of
treatment pre bronchodilation
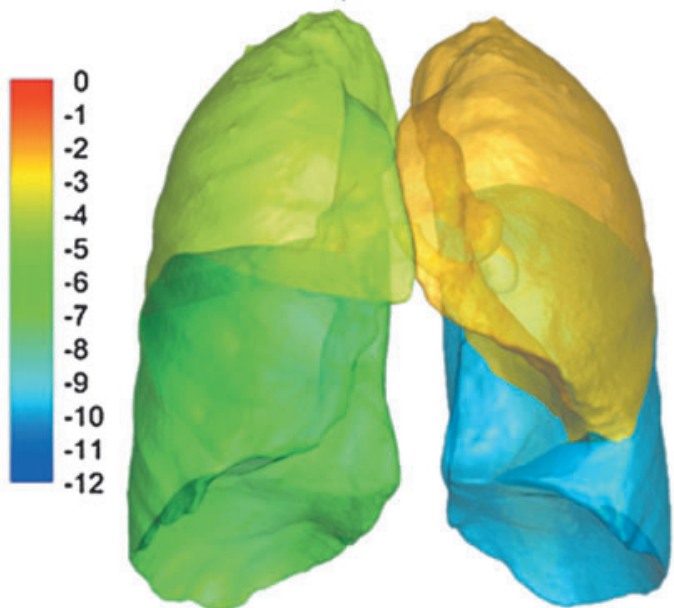

FIG. 5. Changes in iVlobes_TLC (\%pred) $4-6 \mathrm{~h}$ after bronchodilation (left, $p<0.00001)$ ) and after 6 months of treatment with extrafine $\mathrm{BDP} / \mathrm{F}$ (right, $p=0.009$ ) compared to pre-bronchodilation baseline.

the extrafine particle formulation. Table 3 provides an overview of changes in deposition in relation to the changes in hyperinflation for patient 14 . For this patient, it appears that more deposition correlates with reduction in hyperinflation.

\section{Discussion}

The current study aimed to investigate further the effect of extrafine BDP/F on airways geometry using sensitive image-based parameters in both ICS naïve patients and ICS users and to identify the responders. A recent study by Tzani et al. ${ }^{(21)}$ has indicated that the extrafine beclomethasone/ formoterol combination has a beneficial effect on hyperinflation in COPD patients studied using body plethysmography (functional residual capacity, residual volume, and total lung capacity). The effect appeared to be significantly better than a fluticasone/salmeterol combination treatment. The study concluded that, by using extrafine particles, previously suboptimally or untreated regions in the lung could be reached, resulting in an enhanced efficiency. Other studies have demonstrated the added value of combining imaging and computational fluid dynamics to obtain

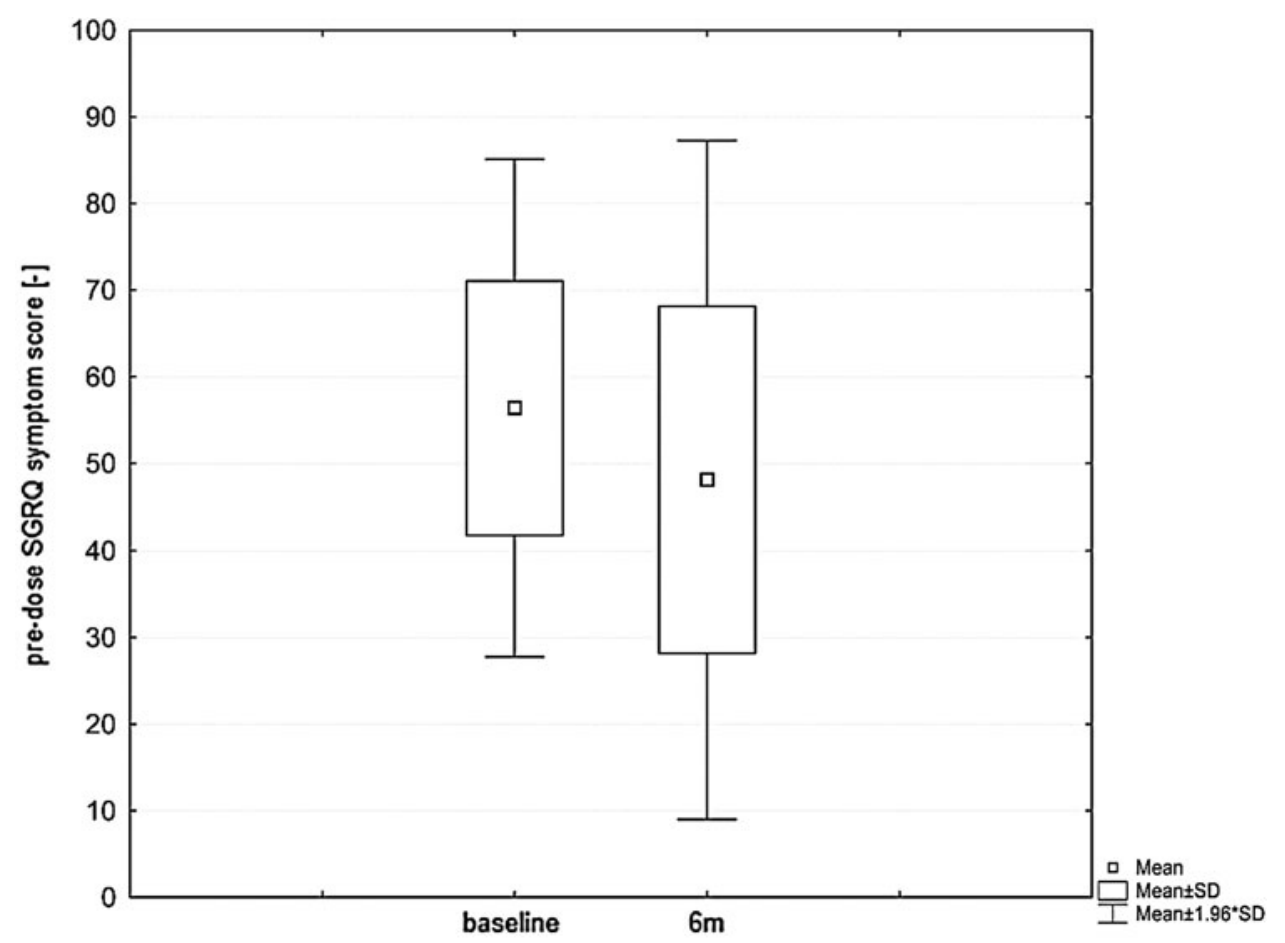

FIG. 6. Changes in SGRQ symptom score at baseline and after 6 months of treatment recorded prior to bronchodilation. 


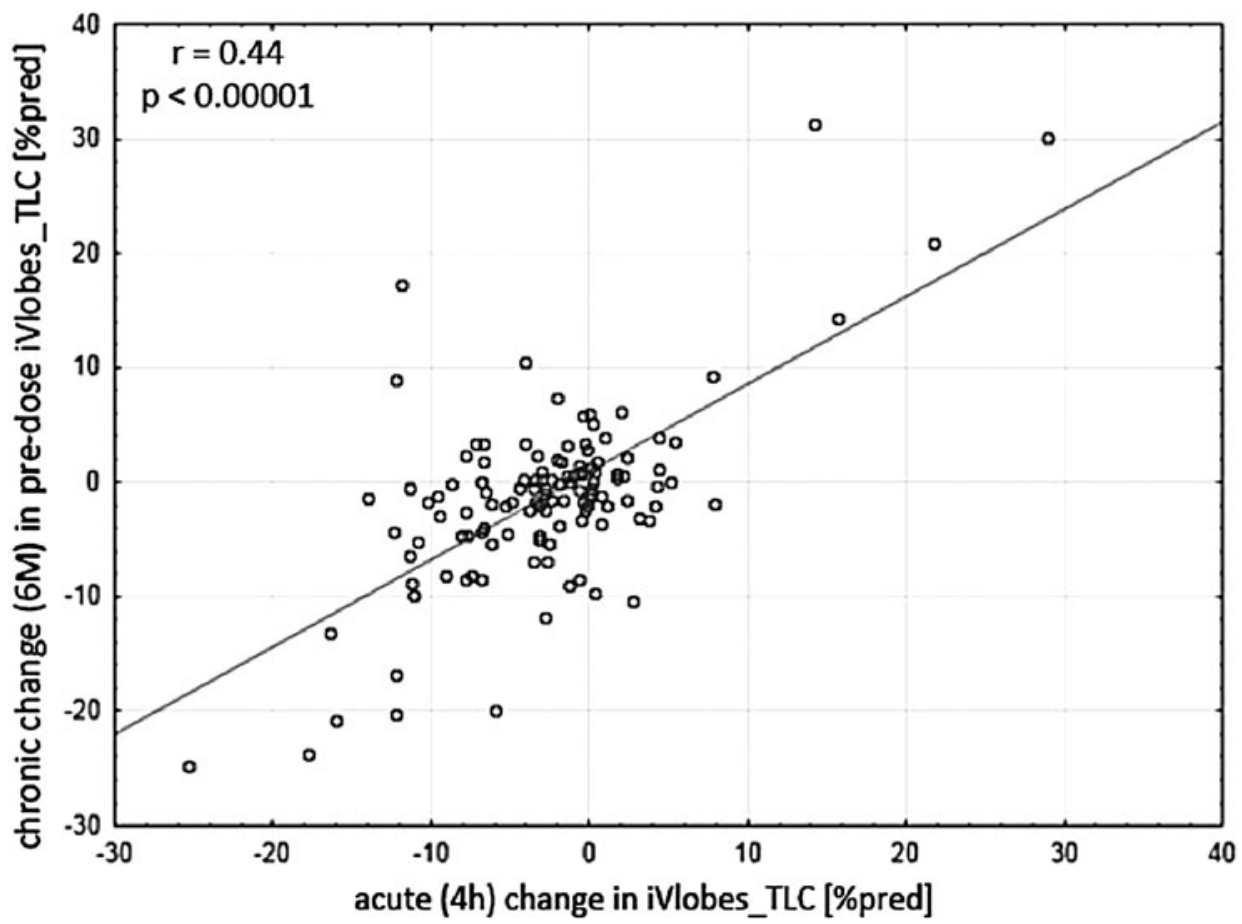

FIG. 7. Change in iVlobes_TLC [\%pred] after 6 months compared to pre-dose Day 1 as a function of the changes in iVlobes_TLC [\% pred] $4-6 \mathrm{~h}$ after the administration on Day 1.

regional information on airway and lobar volumes and resistances. ${ }^{(8,10)}$ The image-based outcome parameters in our study confirmed the results from the previous study using $\mathrm{BDP} / \mathrm{F}$ by also indicating an improvement in lung function and imaging parameters $4-6 \mathrm{~h}$ after the administration using this novel imaging method in patients that were proven clinically stable during at least 6 months when they were treated with non-extrafine particle compounds. The current study was a longitudinal study where subjects switched from the standard therapy including high dose of ICS/LABA or ICS naïve to a new extrafine particle drug. Further improvement in lung function and symptoms was therefore not

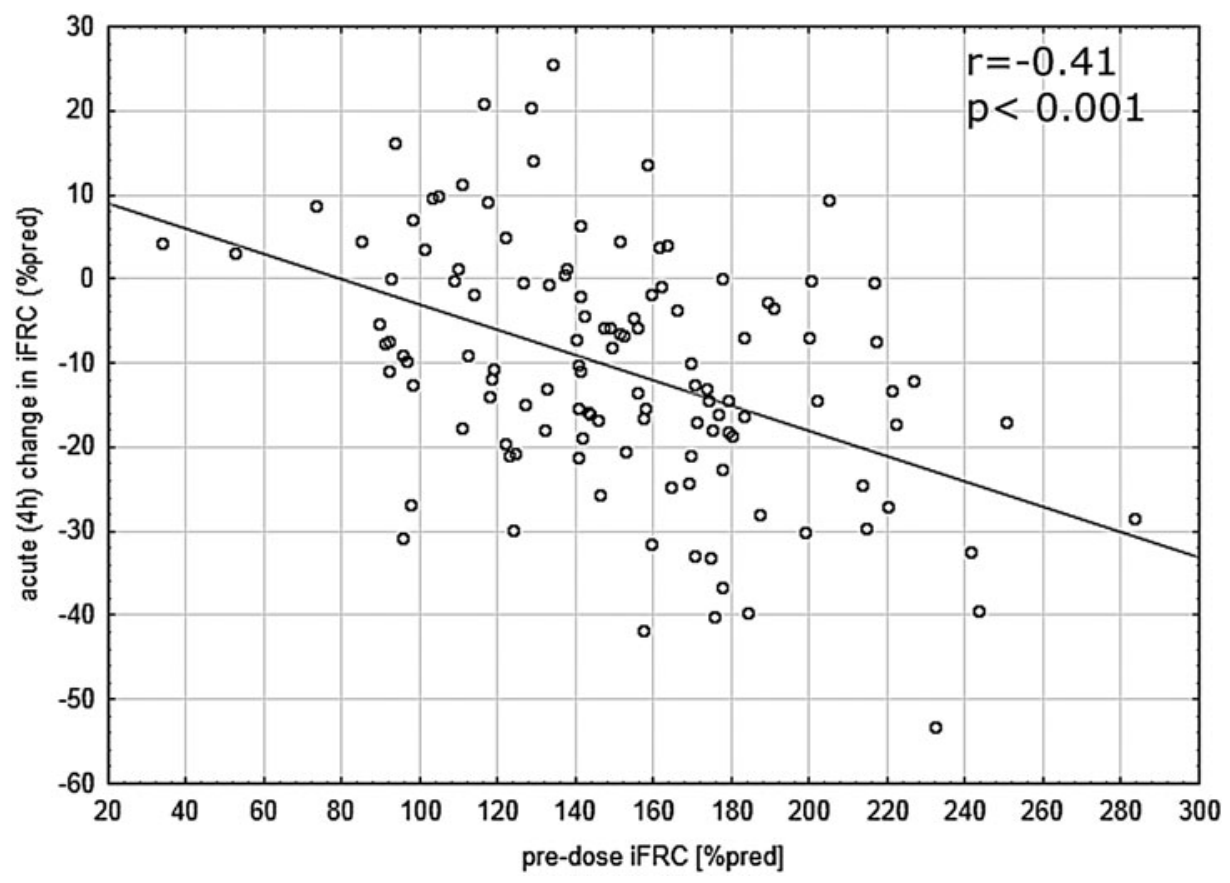

FIG. 8. Change in iVlobes_FRC [\%pred] 4-6h after the administration as a function of the baseline iVlobes_FRC [\% pred]. 

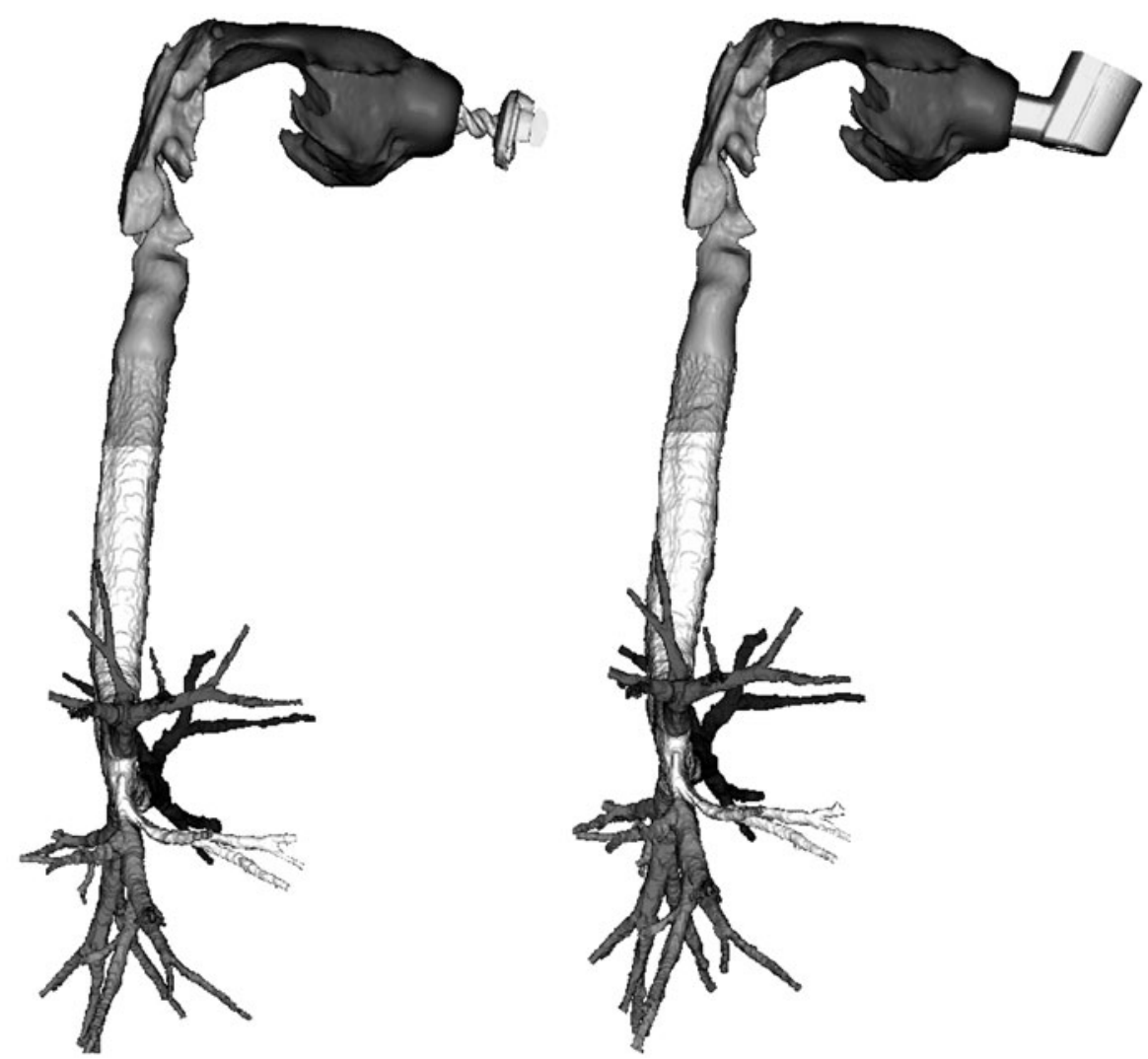

FIG. 9. Coupling of patient 14's airway geometry with the Oxis (left) and Foster (right) inhaler.

expected in the ICS users group, but adequate maintenance was an anticipated end point of the study, which was reached. The $\mathrm{BDP} / \mathrm{F}$ combination used in this study contained a substantially lower dose of ICS and LABA compared to the medication that the patients received prior to the study. The enhanced lung dose due to the smaller particles and the reduced risk of pneumonia were the drivers for selecting this dose. ${ }^{(21)}$

The bodyplethysmography yields aggregate or global values of TLC and FRC while FRI provides lobar information. It can happen that certain lobes reduce in hyperinflation but that the neighboring lobe re-inflates, thereby limiting the signal in the global (body box) parameters obtained using the body box. Tzani et al. ${ }^{(21)}$ reported significant post-dose improvements in TLC and FRC after 12 weeks. Our study looked at pre-dose TLC and FRC measurements over 6 months. Tzani's pre-dose values over 12 weeks were not significantly different, which is in line with our findings. However, we did find significant effects on reduction in FRC after acute bronchodila- tion and a trend in reduction in TLC using plethysmography. On a regional, lobar level (determined using FRI) these findings become highly significant which in turn supports Tzani's overall conclusion.

The CFD-based aerosol deposition analysis showed how the extrafine particles increase the effective lung dose and reach other areas in the lung compared to non-extrafine particle formulation. It must be stated that this analysis focused on the relative deposition differences based on the emitted dose in one patient. More effective inhalers with a larger emitted dose or different formulation characteristics could yield higher overall lung deposition compared to less effective devices. The fact that for the current analysis no exhaled fraction is assumed could imply that the extrafine particle deposition is overestimated. This will be the subject of future research. The role of ICS in moderate COPD patients has always been a topic of ongoing research. The ICS naïve patients in our study, who were considered to be more

Table 3. CFD-Based Deposition and Change in Lobar Volumes for Patient 14

\begin{tabular}{lccccc}
\hline & $\begin{array}{c}\text { \% deposition } \\
\text { Oxis }\end{array}$ & $\begin{array}{c}\text { \% deposition } \\
\text { Foster }\end{array}$ & $\Delta$ deposition $\%$ & $\begin{array}{c}\Delta \text { Volume } \\
\text { FRC [\%p] }\end{array}$ & $\begin{array}{c}\Delta \text { Volume } \\
\text { TLC [\% ] }\end{array}$ \\
\hline Right upper lobe & 7 & 9 & +2 & -24 & -4 \\
Right middle lobe & 2 & 3 & +1 & -6 & -7 \\
Right lower lobe & 15 & 19 & +4 & -32 & -6 \\
Left upper lobe & 6 & 8 & +2 & -21 & -2 \\
Left lower lobe & 8 & 10 & -11 & n/a & n/a \\
Extrathoracic & 62 & 51 & & & \\
\hline
\end{tabular}


moderate COPD patients, actually benefited from the addition of ICS through a reduction in hyperinflation. After 6 months of treatment prior to bronchodilation, most parameters did not indicate a significant difference. Interestingly, the lobar volumes at TLC did reduce significantly in the ICS naïve group. Even though the reduction was limited in absolute terms, it was very consistent over all ICS naïve patients and lobes and highly significant. Classic outcome parameters such as body plethysmography cannot detect these regional changes due to the inherent black box approach. The subtle redistribution of air between the lobes, which appear to be driving the feeling of dyspnea and symptoms, can only be detected using imaging methods that provide regional characteristics of the respiratory system. This could explain why the benefit of ICS in moderate COPD patient is difficult to demonstrate using conventional endpoints. The long-term effect of the product on lobar volumes at TLC appeared to correlate well with the shortterm effect. Approximately $78 \%$ of the short-term postbronchodilation change is still present after 6 months prior to bronchodilation. This in itself is again a hint that previously untreated areas are now potentially reached by the compound, perhaps as a result of a redirection of incoming air due to the reduction in air trapping.

The SGRQ symptom score also indicated that the patients were feeling significantly better. It is well known that a reduction in hyperinflation would lead to an improvement in the patient reported outcome parameters. Therefore it seemed plausible that the extrafine particles reached different lung zones to enhance the reduction in air trapping. Patients who experienced a substantial reduction in hyperinflation (Fig. 5) also reported that they were feeling better after 6 months, reinforcing the link between hyperinflation and patient's well being. This is further confirmed when looking at the relation between the change in dyspnea (MMRC) score and the change in lobar hyperinflation measured at TLC. The MMRC questionnaire aims at assessing the patient's dyspnea on a score between 0 (best) and 4 (worse). A reduction in this score therefore means the patient is improving. Overall this score did not change significantly, but in the subset of patients that reported an improvement, the lobar volumes at TLC were reduced. The correlation between the pre-dose lobar volumes at FRC at baseline and the 4-6h change also indicated that the more severely hyperinflated patients tend to improve most.

The current study showed the potential of novel imaging methods to provide a deeper insight into the mode of action of a drug and detect features that previously could not be analyzed due to the lack of sensitivity. Airway and lobe volumes are direct measurements from the CT data, obtained through segmentation, while the CFD method is used to determine airway resistance and aerosol deposition characteristics. Having the opportunity to assess parameters on a lobar scale is a significantly improvement over the existing techniques such as spirometry and body plethysmography, which typically use a black box approach. The main focus of this trial was on the assessment of changes in hyperinflation using imaging and the maintenance of respiratory function using extrafine $\mathrm{BDP} / \mathrm{F}$ in ICS naïve patients and ICS users. Therefore, this trial did not include a control arm; however it was assured that patients included in the study were stable and controlled by assessing their lung function twice over a 7-month period prior to inclusion. The evidence is suggestive that the observed effects are induced by the treatment. However, future controlled studies need to further confirm these results. The current trial used CFDbased deposition analyses to generate the hypothesis of altered deposition behavior using fine particles in one patient. This finding also needs to be confirmed in a larger sample.

Overall the challenging and heterogeneous nature of COPD calls for a more patient-centered approach taking into account the specific phenotype. Further exploring the potential of new imaging methods could result in a more optimized treatment for COPD patients, resulting in fewer exacerbations and an improved quality of life.

\section{Conclusions}

The study showed that the administration of extrafine BDP/F after 4-6 $\mathrm{h}$ leads to a significant improvement in lung function parameters and hyperinflation as determined by spirometry, body plethysmography, and functional respiratory imaging. Patients previously treated with ICS remained stable despite the lower dose, while ICS naïve patients improved in terms of lobar hyperinflation. A significant improvement in SGRQ symptom score was noted. Patients who improved in terms of hyperinflation also improved their MMRC dyspnea score. FRI seems to be a sensitive biomarker to detect clinically relevant changes that are not detected by spirometry. The next step is to confirm these findings in a controlled trial.

\section{Acknowledgments}

Conception and design: JDB, WV, SV, CVH, GP, RC, WDB; Analysis and interpretation: JDB, WV, SV, CVH, GP, RC, RS, WDB; Drafting the manuscript for important intellectual content: JDB, WV, SV, CVH, GP, RC, WF, RS, WDB.

\section{Author Disclosure Statement}

JDB is founder/shareholder of FluidDA nv; WV, SV, CVH are employed by FluidDA nv; WDB is director of FluidDA nv; GP is employed by Chiesi Pharmaceutici S.P.A. The study was sponsored by Chiesi Pharmaceutici S.P.A

\section{References}

1. Cazzola M, and Dahl R: Inhaled combination therapy with long-acting beta 2-agonists and corticosteroids in stable COPD. Chest. 2004;126:220-237.

2. Hogg JC: Chronic obstructive pulmonary disease: An overview of pathology and pathogenesis. Novartis Found Symp. 2001;234:4-19; discussion 19-26.

3. Kuwano K, Bosken CH, Paré PD, Bai TR, Wiggs BR, and Hogg JC: Small airways dimensions in asthma and in chronic obstructive pulmonary disease. Am Rev Respir Dis. 1993;148:1220-1225.

4. Bosken CH, Wiggs BR, Paré PD, and Hogg JC: Small airway dimensions in smokers with obstruction to airflow. Am Rev Respir Dis. 1990;142:563-570.

5. Paré PD, Brooks LA, Coppin CA, Wright JL, Kennedy S, Dahlby R, Mink S, and Hogg JC: Density-dependence of maximal expiratory flow and its correlation with small airway disease in smokers. Am Rev Respir Dis. 1985;131: 521-526. 
6. Grenier PA, Beigelman-Aubry C, Fétita C, Prêteux F, Brauner MW, and Lenoir S: New frontiers in CT imaging of airway disease. Eur Radiol. 2002;12:1022-1044.

7. De Backer JW, Vos WG, Vinchurkar SC, Claes R, Drollmann A, Wulfrank D, Parizel PM, Germonpré P, and De Backer W: Validation of computational fluid dynamics in CT-based airway models with SPECT/CT. Radiology. 2010; 257:854-862.

8. De Backer L, Vos W, De Backer J, Van Holsbeke C, Vinchurkar S, and De Backer W: The acute effect of budesonide/formoterol in COPD patients: A multi-slice computed tomography and lung function study. Eur Respir J. 2012; 40:298-305.

9. De Backer L, Vos W, Salgado R, De Backer J, Devolder A, Verhulst S, Claes R, Germonpre P, and De Backer W: Functional imaging using computer methods to compare the effect of salbutamol and ipratropium bromide in patient-specific airway models of COPD. Int J Chron Obstruct Pulmon Dis. 2011;2011:6:637-646.

10. De Backer JW, Vos WG, Devolder A, Verhulst SL, Germonpré P, Wuyts FL, Parizel PM, and De Backer W: Computational fluid dynamics can detect changes in airway resistance in asthmatics after acute bronchodilation. J Biomech. 2008;41:106-113.

11. Hanania NA: The impact of inhaled corticosteroid and long-acting beta-agonist combination therapy on outcomes in COPD. Pulm Pharmacol Ther. 2008;21:540-550.

12. Mahler DA, Wire P, Horstman D, Chang C-N, Yates J, Fischer T, and Shah T: Effectiveness of fluticasone propionate and salmeterol combination delivered via the Diskus device in the treatment of chronic obstructive pulmonary disease. Am J Respir Crit Care Med. 2002;166: 1084-1091.

13. Szafranski W, Cukier A, Ramirez A, Menga G, Sansores R, Nahabedian S, Peterson S, and Olsson H: Efficacy and safety of budesonide/formoterol in the management of chronic obstructive pulmonary disease. Eur Respir J Off J Eur Soc Clin Respir Physiol. 2003;21:74-81.

14. Kardos P, Wencker M, Glaab T, and Vogelmeier C: Impact of salmeterol/fluticasone propionate versus salmeterol on exacerbations in severe chronic obstructive pulmonary disease. Am J Respir Crit Care Med. 2007;175:144-149.

15. Calverley PMA, Anderson JA, Celli B, Ferguson GT, Jenkins C, Jones PW, Yates JC, and Vestbo J: Salmeterol and fluticasone propionate and survival in chronic obstructive pulmonary disease. N Engl J Med. 2007;356: 775-789.

16. Bousquet J, and Dell'anna C: Modulite technology in the development of formoterol HFA pMDI: Clinical evidence and future opportunities. Expert Rev Respir Med. 2008; 2:27-36.

17. Janssens HM, and Tiddens HAWM: Aerosol therapy: The special needs of young children. Paediatr Respir Rev. 2006; 7:S83-85.

18. De Backer W, Devolder A, Poli G, Acerbi D, Monno R, Herpich C, Sommerer K, Meyer T, and Mariotti F: Lung deposition of BDP/formoterol HFA pMDI in healthy volunteers, asthmatic, and COPD patients. J Aerosol Med Pulm Drug Deliv. 2010;23:137-148.

19. De Backer JW, Vos WG, Gorlé CD, Germonpré P, Partoens B, Wuyts FL, Parizel PM, and De Backer W: Flow analyses in the lower airways: Patient-specific model and boundary conditions. Med Eng Phys. 2008;30:872-879.

20. Weuthen T, Roeder S, Brand P, Müllinger B, and Scheuch $\mathrm{G}$ : In vitro testing of two formoterol dry powder inhalers at different flow rates. J Aerosol Med. 2002;15:297-303.

21. Tzani P, Crisafulli E, Nicolini G, Aiello M, Chetta A, Clini EM, and Olivieri D: Effects of beclomethasone/formoterol fixed combination on lung hyperinflation and dyspnea in COPD patients. Int $\mathrm{J}$ Chron Obstruct Pulmon Dis. 2011;6:503-509.

Received on May 28, 2013 in final form, April 22, 2014

Reviewed by: Chantal Darquenne Lars Borgström

Address correspondence to: Jan De Backer, MSc, PhD

Fluid DA NV

Groeningenlei 132 2550 Kontich Belgium

E-mail: Jan.DeBacker@FluidDA.com 